\title{
Rolandic epilepsy-speech dyspraxia syndrome
}

INSERM

\section{Source}

INSERM. (1999). Orphanet: an online rare disease and orphan drug data base. Rolandic epilepsy-speech dyspraxia syndrome. ORPHA:163721

Rolandic epilepsy-speech dyspraxia syndrome is a rare, genetic epilepsy characterized by speech disorder (including a range of symptoms from dysarthria, speech dyspraxia, receptive and expressive language delay/regression and acquired aphasia to subtle impairments of conversational speech) and epilepsy (mostly focal and secondary generalized childhood-onset seizures, sometimes with aura). Mild to severe intellectual disability may also be observed. 